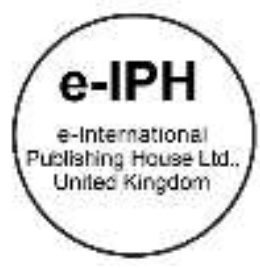

\title{
The Role of Home Pocket Garden to Achieve Quality of Life during the Pandemic Era
}

\author{
Aliyah Nur Zafirah Sanusi 1, Fadzidah Abdullah 1, Rosniza Othman 2, \\ Aida Kesuma Azmin ${ }^{1}$, Zeenat Begam Yusof ${ }^{1}$, Nayeem Asif 1
}

\begin{abstract}
${ }^{1}$ Department of Architecture, Kulliyyah of Architecture and Environmental Design, International Islamic University Malaysia, Malaysia, ${ }^{2}$ Faculty of Engineering, Prince Mugrin bin Abdulaziz University, Saudi Arabia
\end{abstract}

aliyah@iium.edu.my, fadzidah@iium.edu.my, r.othman@upm.edu.sa, aida_kesuma@iium.edu.my, zeensoni@iium.edu.my, nayeem@iium.edu.my Tel: +60193890991

\begin{abstract}
Before the pandemic, residents in the Klang Valley tend to prioritize indoor living space to outdoor. This study analyzed the importance of outdoor green space in residential buildings. It consists of two objectives; to identify the type of home pocket gardens used and to evaluate the significant impact of home pocket gardens on the quality of life (QOL) during the pandemic. A survey was conducted using a five-point Likert scale and distributed to three housing communities within the Klang Valley. The finding shows the positive role of the Home Pocket Garden on the Quality of Life during the pandemic.

Keywords: Pocket Garden, Quality of Life.

eISSN: 2398-42870 2021. The Authors. Published for AMER ABRA cE-Bs by e-International Publishing House, Ltd., UK. This is an open access article under the CC BYNCND license (http://creativecommons.org/licenses/by-nc-nd/4.0/). Peer-review under responsibility of AMER (Association of Malaysian Environment-Behaviour Researchers), ABRA (Association of Behavioural Researchers on Asians/Africans/Arabians) and CE-Bs (Centre for Environment-Behaviour Studies), Faculty of Architecture, Planning \& Surveying, Universiti Teknologi MARA, Malaysia.

DOI: https://doi.org/10.21834/ebpj.v6i18.3079
\end{abstract}

\subsection{Introduction}

The current Covid-19 health crisis is not only affecting physical but also psychological. The enforcement of movement control order (MCO) has affected the daily routine in all households across the globe. Daily activities take place at home during the MCO. The only escape space is the outdoor space within their house compound.

The Laws of Malaysia Uniform Building By-Law, Clause 32(1)(a) stated the necessity of providing open space in residential buildings. "The open space for buildings abutting a street and back-lane shall be in respect of residential buildings, not less than one-third of the built-on area of the building lot" (UBBL, 2006, 14th edition). Despite the law, before the pandemic, a study in the Klang Valley concluded that the residents found that the original house design did not fulfill their needs and satisfaction indoors. Most of the house renovation results in the extension of the built-up area and loss of open space, leaving minimal outdoor space to function as a car porch (Omar et al., 2012).

The pandemic lockdown has affected many residents and their living conditions preference. A survey, conducted on 8177 , university students in Italy after two months of movement control order (MCO) implementation. The findings show a strong relationship between poor housing and the increasing risk of developing depression symptoms during the MCO. Here, poor housing refers to poor views and a lack of green areas. It recommends a house with better views facing green spaces to maintain healthy mental well-being (Amerio et al., 2020). Zainudeen et al. (2021) carried out a study on the psychosocial impact of the COVID-19 pandemic on Malaysian families. A large portion

eISSN: 2398-4287@ 2021. The Authors. Published for AMER ABRA CE-Bs by e-International Publishing House, Ltd., UK. This is an open access article under the CC BYNCND license (http://creativecommons.org/licenses/by-nc-nd/4.0/). Peer-review under responsibility of AMER (Association of Malaysian Environment-Behaviour Researchers), ABRA (Association of Behavioural Researchers on Asians/Africans/Arabians) and CE-Bs (Centre for Environment-Behaviour Studies), Faculty of Architecture, Planning \& Surveying, Universiti Teknologi MARA, Malaysia.

DOI: https://doi.org/10.21834/ebpj.v6i18.3079 
of Malaysian families was affected psychologically by the pandemic. The study suggested implementing future psychological support interventions, which should be made available to the community (Zainudeen et al., 2021).

This study investigated the role of outdoor green space in residential buildings. The green space is also known as "Home Pocket Garden" or HPG. The definition of Home Pocket Garden is a portion of the house's outdoor space that has plants growing. This study consists of two objectives. The first objective is to identify the type of home pocket gardens used in homes. The second objective is to evaluate the significant impact of home pocket gardens on the quality of life (QOL) during the pandemic. Before the pandemic, the "a city in a park" concept was proposed by the former Prime Minister of Malaysia, His Excellency Tun Dr. Mahathir Mohamad. In response to the concept, the Federal Department of Town and Country Planning, Peninsular Malaysia (FDTCP) issued Planning Standard Guidelines for Open Spaces and Recreation (JBPD 7/2000). The local authorities (LAs) used the guideline in implementing green open spaces in their town planning and building projects to achieve Malaysia's vision as a "Garden Nation" (lbrahim et al., 2013). This study aims to strengthen the importance of achieving the vision for the well-being of the Nation, particularly in the pandemic era. The study also responded to the United Nation's Sustainable Development Goals; no hunger (SDG 2), good health (SDG 3), sustainable cities and communities (SDG 11), and partnership for the goals (SDG 17) (Williams and Blaiklock, 2015).

\subsection{Literature Review}

Research on Quality of Life and the psychological impact of home pocket gardens have been carried out by researchers. The following are theories and findings that are relevant to this study, which determined the essence of QOL and the significant impact of home pocket gardens on QOL.

\subsection{The Essence of Quality of Life}

Quality of Life (QOL) is a concept defined as "the degree to which the experience of an individual's life satisfies that individual's wants and needs in both physical and psychological" (Rice, 1984). Vischer (1989) came up with a pyramid of three types of comfort; physical, functional, and psychological comfort (Fig. 1). Physical comfort is the comfort sensation feeling a human body. Functional comfort is adequate space for the occupants to function well. Psychological comfort is at the top of the pyramid, which is achieved when the occupants are satisfied with their living environment and well-being (Vischer, 2015). This study is relevant because the MCO has enforced everyone to work from home.

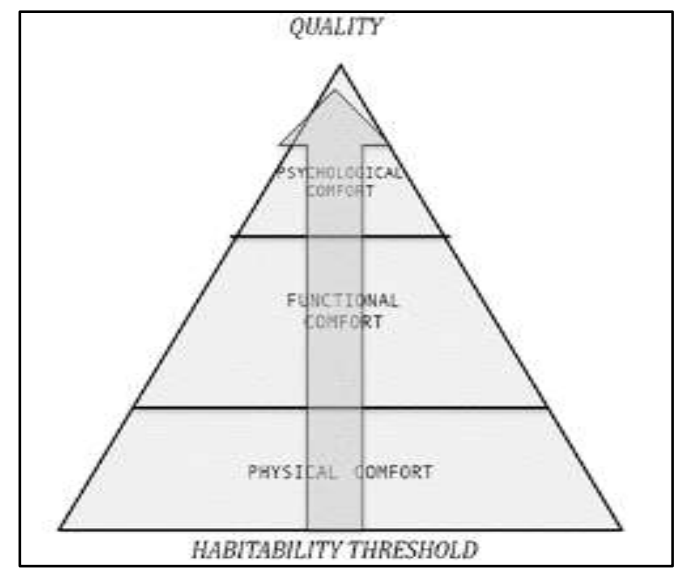

Fig. 1: The pyramid of three types of comfort towards Quality of Life.

(Source: Vischer, 1989)

Several indicators measure the Quality of Life. In Sweden, the Quality of Life indicators are Having, Loving, and Being. Having related to personal needs and materials, Loving is related to social relationships with other people, and Being relates to participation, personal growth, and relation towards nature (Allardt, 1993). The QOL indicators in a developed country include materials, social relationships, and their activities with context and nature. The QOL does not only rely on the ownership of resources (Allardt, 1993).

In Amman, Jordan, the domains that affect the Quality of Life (QOL) in the city of Amman. Amman is similar to Kuala Lumpur where both are within developing countries. It was concluded 11 domains differ in percentage. The domain that have a larger effect were environment, health, housing, and economy, while the domains that affect the least was culture and recreation (Fig. 1). One of the indicators towards QOL is satisfaction with one's housing and living conditions (Ali et al., 2009). 


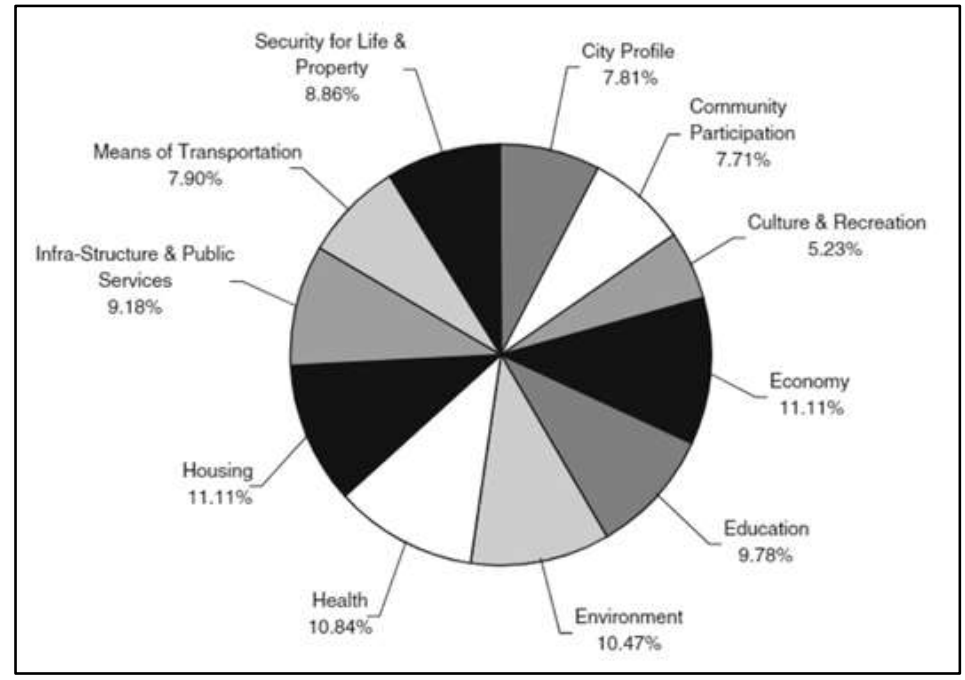

Fig. 2: Percentage of the domains affecting QOL in Amman, Jordan.

(Source: Ali et al., 2009)

In the local context, a study in two housing estates in Johor concluded that four principles influence the residents' level of well-being, one of which is appropriate landscaping (Ismail and Muslim, 2017).

\subsection{The Impact of Home Pocket Garden}

A study in Taman Melati Mastika (TMM), Kuala Lumpur concluded that residents facing green areas are the most satisfied with their living conditions as compared to the other houses that face away from the green areas (Bakar et al., 2016). A study was carried in Taman Aman Petaling Jaya on how the neighbourhood park reduces the stress of the neighbourhood residents. Among many elements in the park, the residents find the natural elements help to reduce their stress (Hussein, 2021).

In Barcelona, Spain, gardening activities were proposed for mental health disorders residents on urban rooftop gardens. From field observation, gardening benefits their life's mental well-being. It concludes that gardening is associated with personal development and emotional well-being. The gardening activities provide social inclusion and sense of purpose (Triguero-Mas et al., 2020). Urban dwellers in Sri Lanka have found that home gardening fulfills at least one or two daily nutrition from their vegetable products. The garden activities act as a stress release, healthy family interaction, and social unity during the Covid-19 pandemic situation (Dissanayake and Dilini, 2020).

Greeneries also can improve the air quality for a better Environmental Quality (EQ) (Farid et al., 2016). This provides good health and well-being which is part of QOL. This is supported by a survey carried out in Oman. It was found that the residents were motivated to do gardening for various reasons. The most dominant motivation was aesthetic, followed by natural shading, past-time activities, and food source (Al-Mayahi et al., 2019).

\subsection{Methodology}

This study aims to understand owners' perceptions of home pocket gardens during the Covid-19 pandemic. Fig. 2 shows the research methodology flow chart.

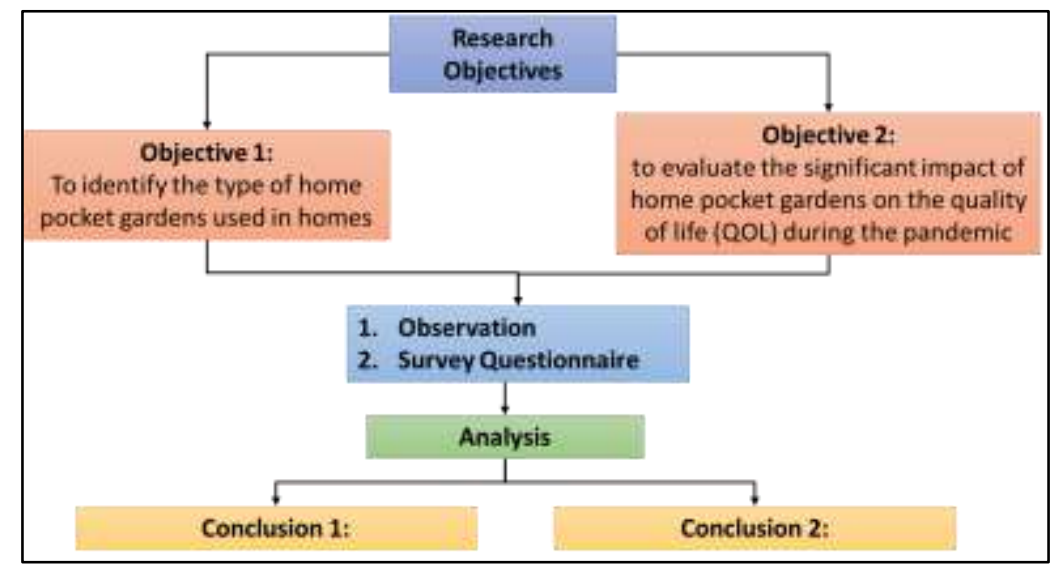

Fig. 3: Research Methodology flow chart. 


\subsection{Research Area}

Three housing areas were selected for this study; Taman Mutiara Gombak 1, Gombak, Selangor; Taman Bukit Utama, Ampang, Selangor; and Taman Bukit Bandaraya, Bangsar, Kuala Lumpur. The chosen housing typologies are landed properties, and the residents are diverse in ages, races, and occupations. The survey questionnaires were distributed to the three housing areas, in the proximity of Kuala Lumpur. The research method begins with observation of HPG in the chosen housing area, to achieve the first objective. A survey was conducted through an online survey questionnaire. This survey responded to the second objective.

\subsection{Sample and Questionnaire}

The survey questionnaires were formulated based on the literature reviews. They are food security; social and sustainable living; and finally, health, and wellbeing (Mayahi et al. 2019). The questionnaire was administered through official online housing social media, such as Whatsapp groups and personal messages. The questionnaire contains Part A: Respondents' Background, Part B: Home Pocket Garden Description, and Part C: Perception Towards Home Pocket Gardens. The questionnaire used a Likert scale of 1: Strongly agree, 2: Agree, 3 Neutral, 4 Disagree, 5 Strongly disagree. It was distributed to 292 housing online community population, namely 124 residents from Taman Bukit Bandaraya, 96 from Taman Bukit Utama and 72 from Taman Mutiara Gombak 1. A total of 30 residents had responded to the survey. The response rate of the survey is $10.3 \%$ of the total population. This result is sufficient for further analysis (Krejcie \& Morgan, 1970).

This study uses the democratic (participatory) approach, which is also called a 'community' or 'bottom-up' approach (Wegener and Huner, 2001). The democratic approach gains information from local ordinary citizens.

\subsection{Limitation}

There are several limitations to this study. The questionnaires were distributed online. Hence, it is limited to those with an internet connection. The survey questionnaires were distributed in Bahasa Malaysia and English to consider the issues of languages barrier. The survey was conducted in landed residential buildings, excluding the high-rise residential buildings.

\subsection{Findings}

\subsection{Demography of the Respondents}

As mentioned earlier, out of 292 housing online community population, 30 responded to the survey. Among the 30 respondents, there were 25 females and 5 males. The respondents were mainly from the middle-aged group. $40 \%$ are between 41 to 50 years old and $34 \%$ are between 51 to 60 years old. $20 \%$ are elderlies, above 61 years old. $53 \%$ of the respondents live in a terraced house, $34 \%$ live in semiD, end lot, and corner lot and only $13 \%$ live in a bungalow. The majority of the houses have between 4 to 6 occupants. The majority of the respondents fall under the middle range and have high household incomes (Fig. 4).

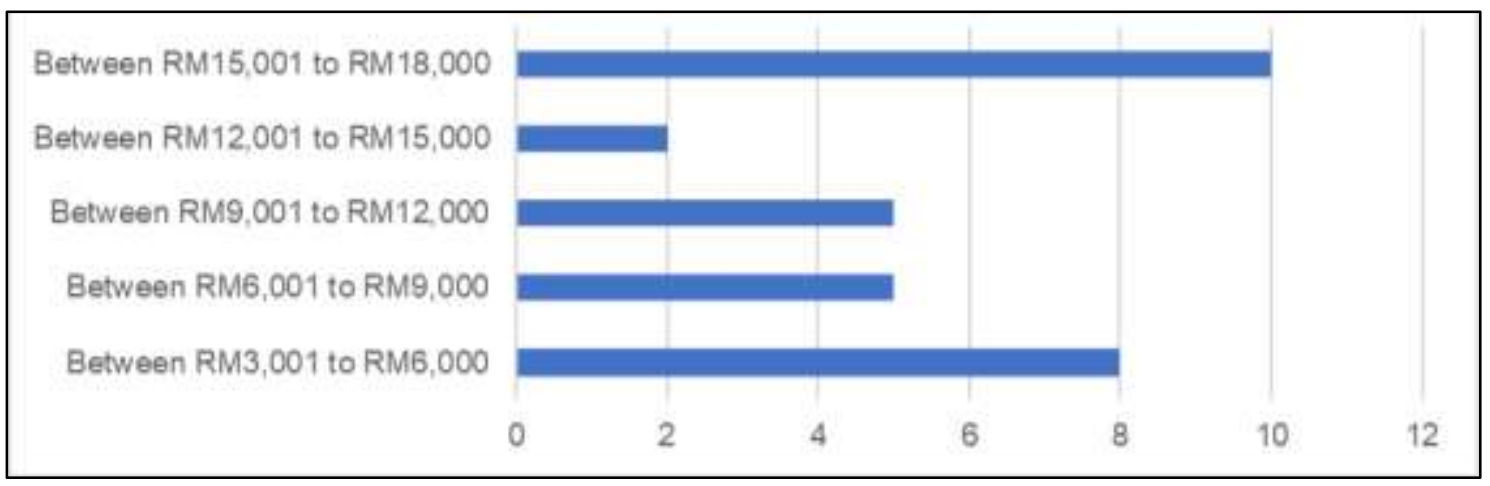

Fig. 4: The household income of the respondents.

Fig. 5 presents the data on professions. Majority of the respondents are either self-employed, work or own a private company or housewives (Fig. 5). 


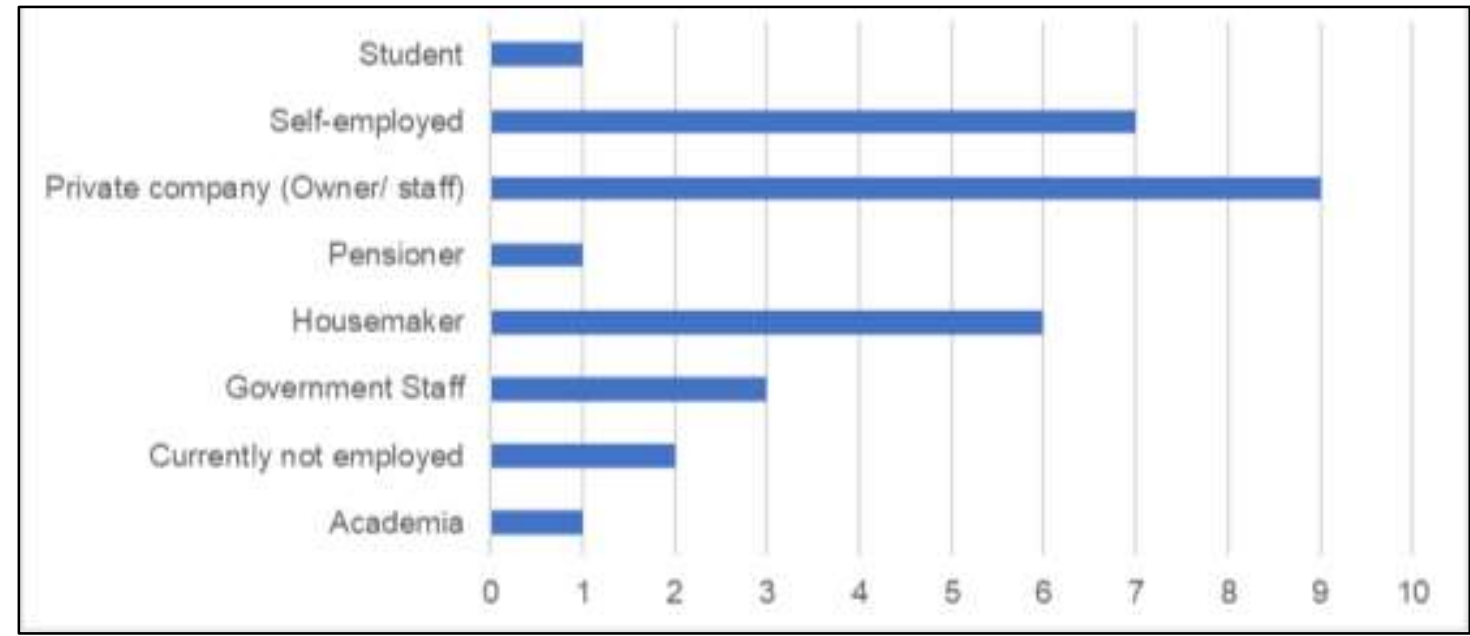

Fig. 5: Professions of the respondents.

\subsection{Type of Home Pocket Garden and Gardening Activities}

$63 \%$ of the respondents have a home pocket garden before and during the Covid-19 pandemic. Fig. $6(\mathrm{a})$ and $(\mathrm{b})$ show the same percentage of residents that have a home pocket garden before and during the pandemic.

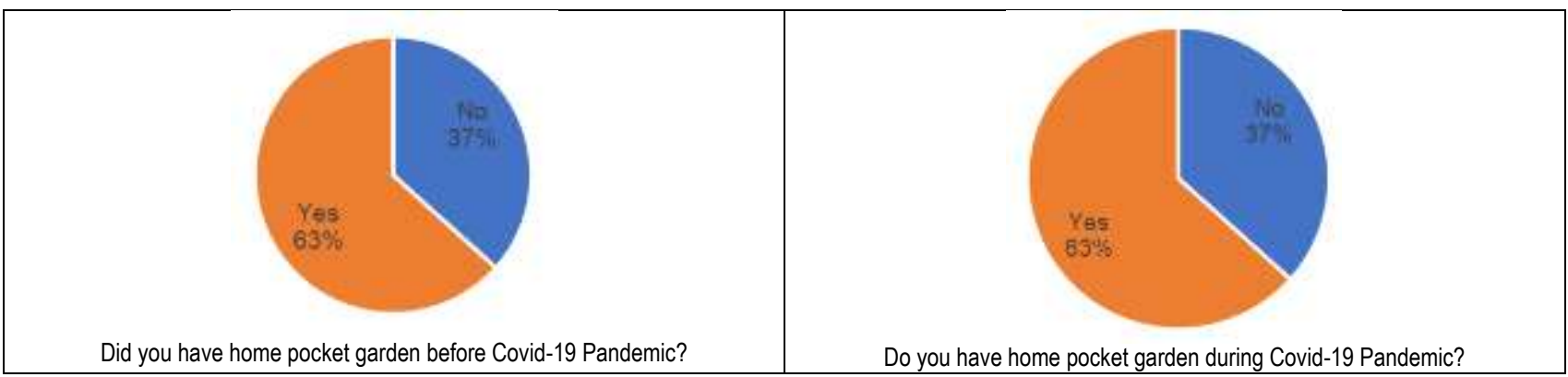

(a)

(b)

Fig. 6 (a) Residents with home pocket garden before pandemic; (b) Residents with home pocket garden during the Covid-19 pandemic.

However, there are differences in respondents. 4 respondents had a home pocket garden before the pandemic but did not continue during the pandemic. Similarly, 4 respondents did not have any home pocket garden but started having one during the pandemic. 9 of the respondents, who did not have a Home Pocket Garden, intended to have one after the MCO. Only 2 respondents who do not have a home pocket garden during the pandemic and do not plan to have one afterward (Fig. 7). Their income is within the high range, between RM15,001 to RM18,000 per month. On average both of them have limited land available of land for gardening, between $1 \mathrm{~m}^{2}$ to $3 \mathrm{~m}^{2}$.

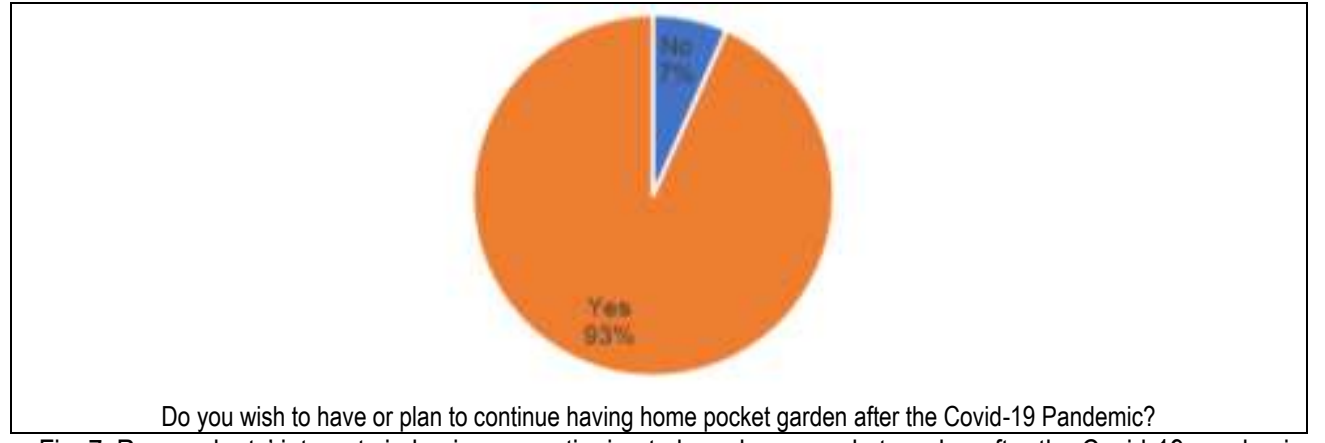

Fig. 7: Respondents' interests in having or continuing to have home pocket garden after the Covid-19 pandemic.

Fig. 8 shows that the majority location of home pocket garden is in the front yards. 


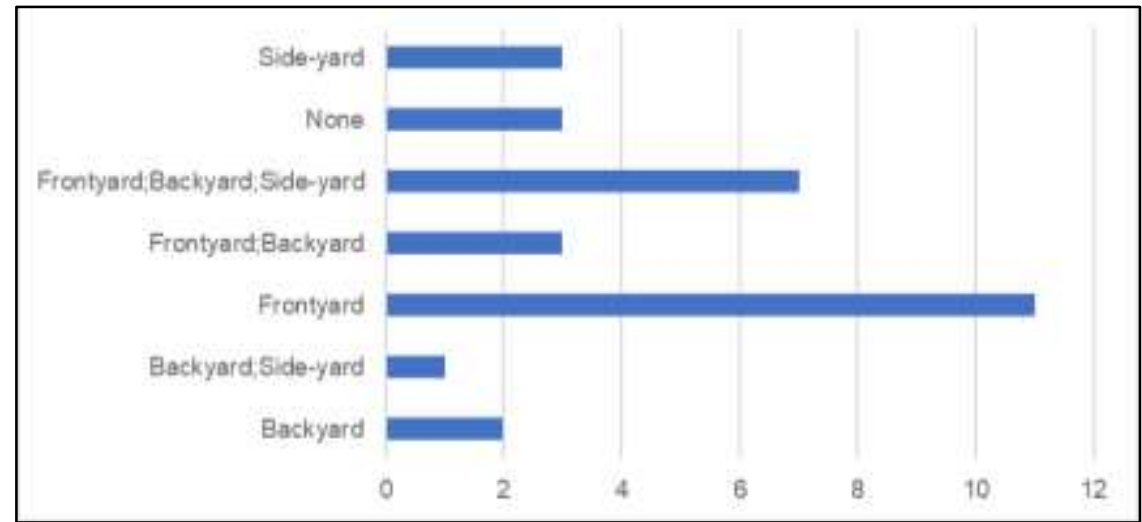

Fig. 8: Location of home pocket garden.

Fig. 9 shows that the majority of the respondents (34\%) have small home pocket garden, between $1 \mathrm{~m}^{2}$ to $3 \mathrm{~m}^{2}$ area.

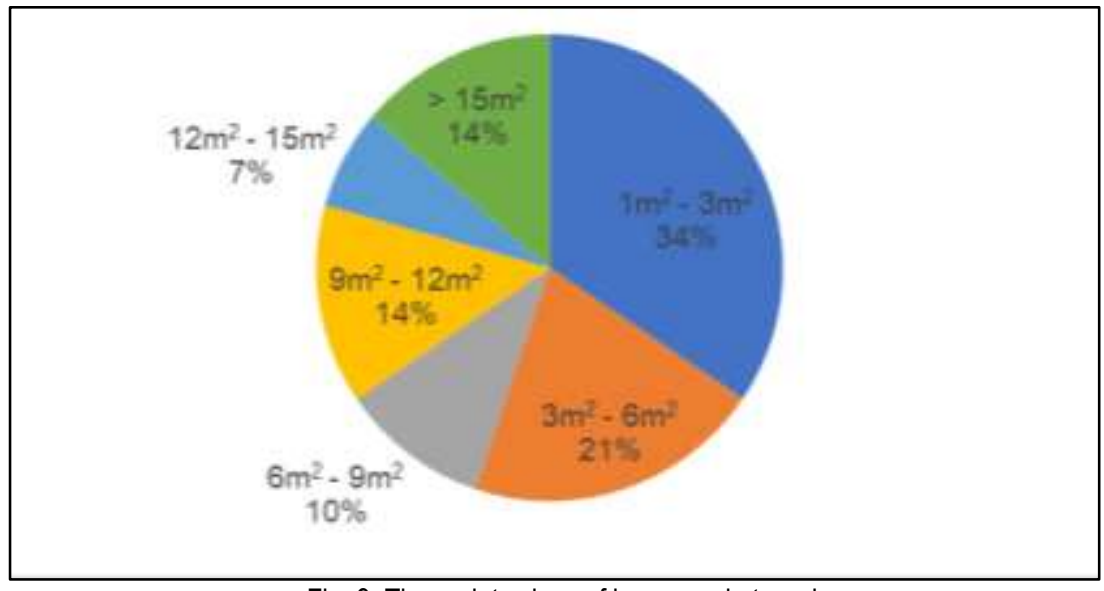

Fig. 9: The variety sizes of home pocket garden.

The majority of the respondents do gardening once a week. There are many types of home pocket gardens found in the studied areas. $73 \%$ of the respondents have the potted plants' type garden, $60 \%$ have container and planter box gardens. $20 \%$ of the respondents have a rooftop garden (Fig. 10).

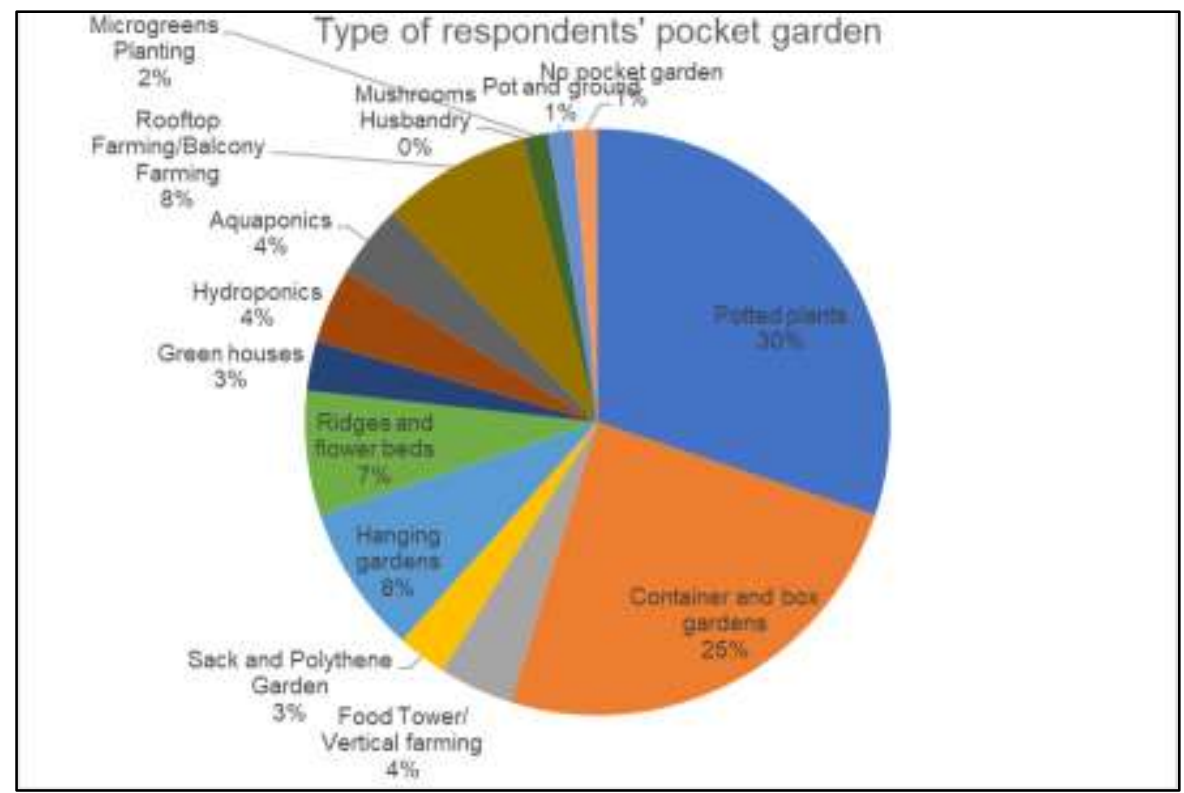

Fig. 10: Various types of home pocket garden. 
Fig. 11 (a) shows an example of ptted plants in a terraced house in Taman Bukit Bandaraya. Fig. 11 (b) shows an example of big fruit tree planting in a house in Taman Bukit Utama. The homeowner grows papaya trees. Fig. 11 (c) and (d) show examples of a hydroponic pocket garden in Taman Mutiara Gombak 1. The house owner grows vegetables and herbs in her hydroponic home pocket garden.

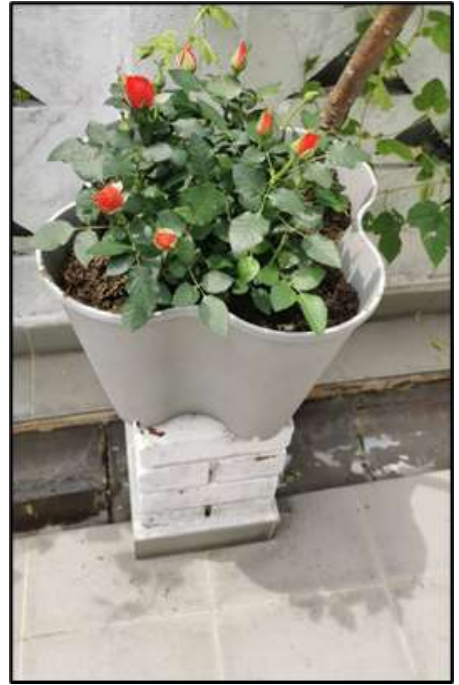

(a)

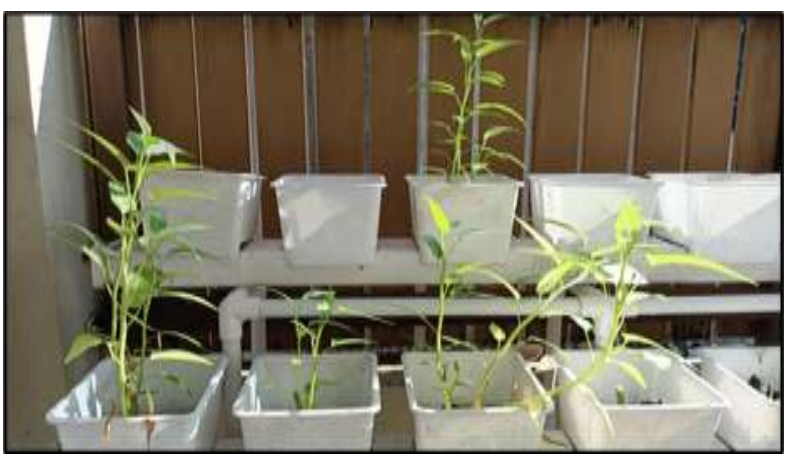

(c)

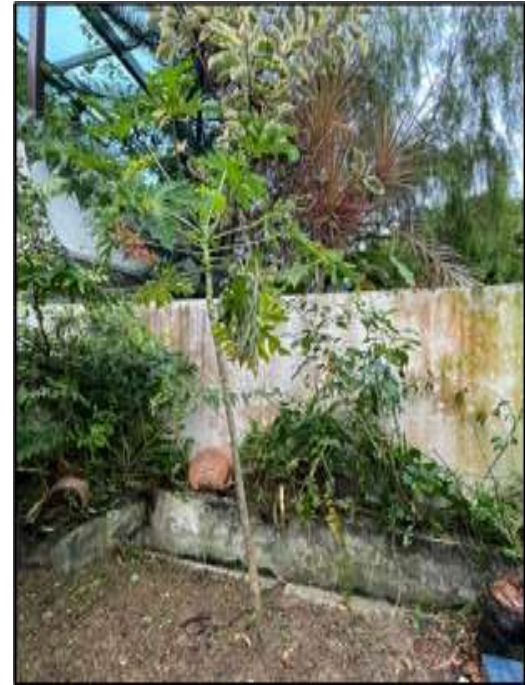

(b)

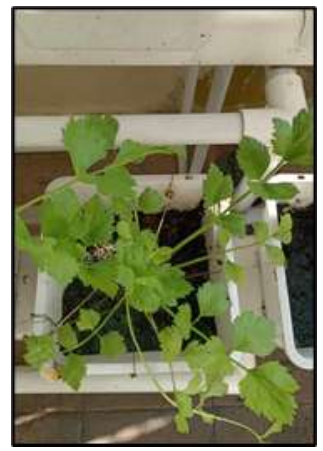

(d)

Fig. 11 (a) Potted plant in Taman Bukit Bandaraya; (b) Papaya tree in Taman Bukit Utama; (c) \& (d) Hydrophonic home pocket garden in Taman Mutiara Gombak 1

(Source: Pictures taken by residents of Taman Bukit Bandaraya, Taman Bukit Utama and Taman Mutiara Gombak 1, 2021)

Fig. 12 shows an example of a combination of a home pocket garden and an outdoor family area in a house in Taman Bukit Utama. Both garden and family areas were connected to allow interaction among all family members of different age groups and hobbies. It shows a spatial relationship between the home pocket garden and the outdoor family seating area.

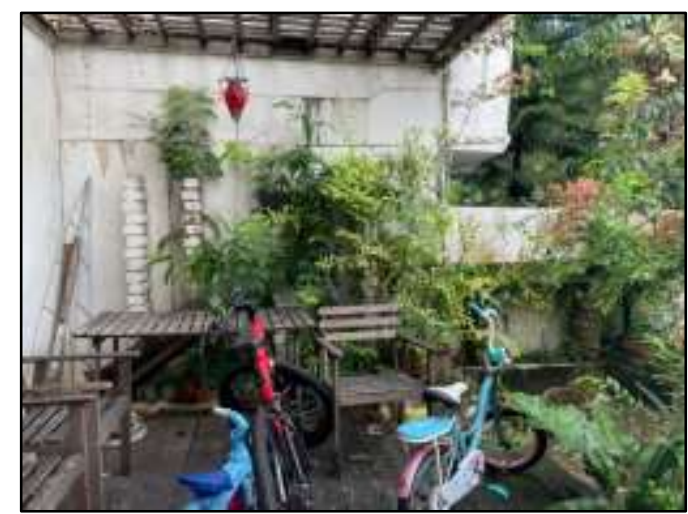

Fig. 12: An example of spatial relationship between home pocket garden and outdoor family seating area.

(Source: Pictures taken by a resident of Taman Bukit Utama, 2021) 


\subsection{Satisfaction on Home Pocket Garden}

Overall, the majority of the respondents voted moderately, very, and extremely satisfied with their home pocket garden and the size of their home pocket garden. Fig. 13 (a) and (b) show the percentage of their satisfaction. A total of $80 \%$ are either moderately, very, or extremely satisfied with their home pocket gardens. Meanwhile, a total of $70 \%$ are either moderately, very, or extremely satisfied with the size of their home pocket gardens. Some of the respondents are happy with their home pocket gardens but they are not satisfied with the size of their home pocket gardens.

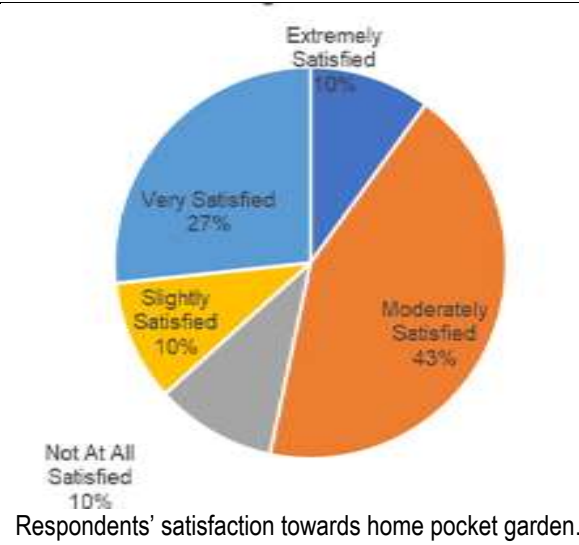

(a)

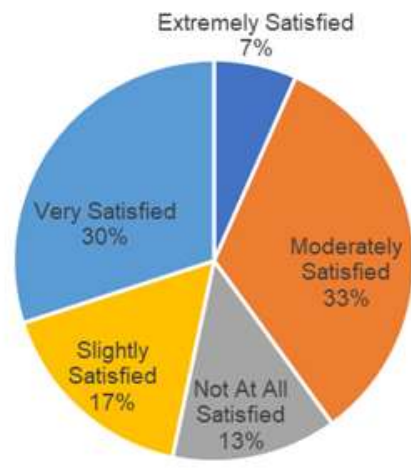

Respondents' satisfaction towards the size of home pocket garden.

Fig. 13 (a) Percentage of respondents' satisfaction towards their home pocket garden; (b) Percentage of respondents' satisfaction towards the size of home pocket garden.

Respondents who were not satisfied with the size of the pocket home garden have minimal land size, between $1 \mathrm{~m} 2$ to $3 \mathrm{~m} 2$, available for gardening. Among the 3 extremely satisfied respondents, 2 of the respondents have more than $15 \mathrm{~m} 2$ area of the home pocket garden and 1 of the respondents has between $3 \mathrm{~m} 2$ to $6 \mathrm{~m} 2$ area of the home pocket garden.

4.4 Perceptions Towards the Positive Role of Home Pocket Garden (HPG) on QOL during the Covid-19 Pandemic

This study also surveyed perceptions towards the positive role of the home pocket garden on QOL during the Covid-19 pandemic. Most of the respondents have agreed that HPG can enhance food security (SDG 2) for the family during the pandemic, with a mean value of 3.7 (Fig. 14).

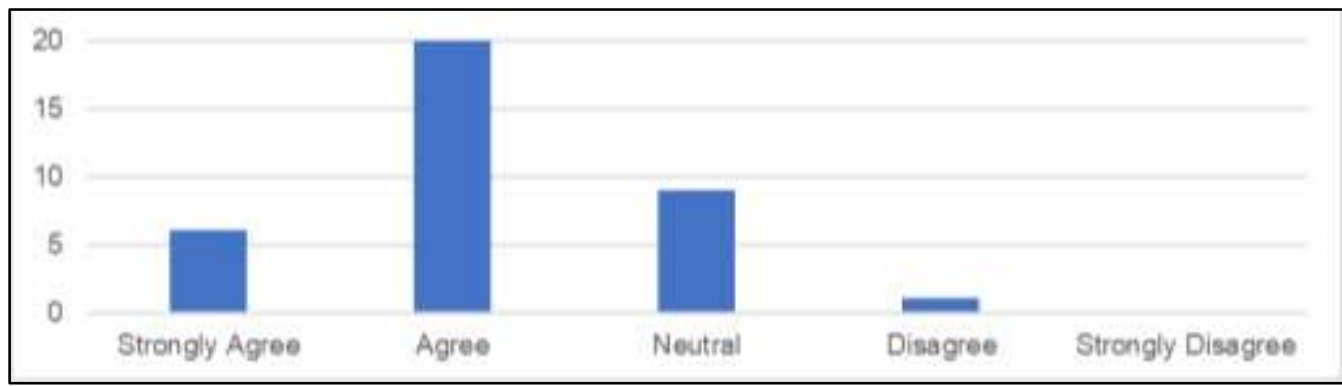

Fig. 14: The impact of home pocket garden to food security (SDG 2)

Four of the survey questionnaires were related to the impact of HPG on the sustainable cities and communities (SDG 11).

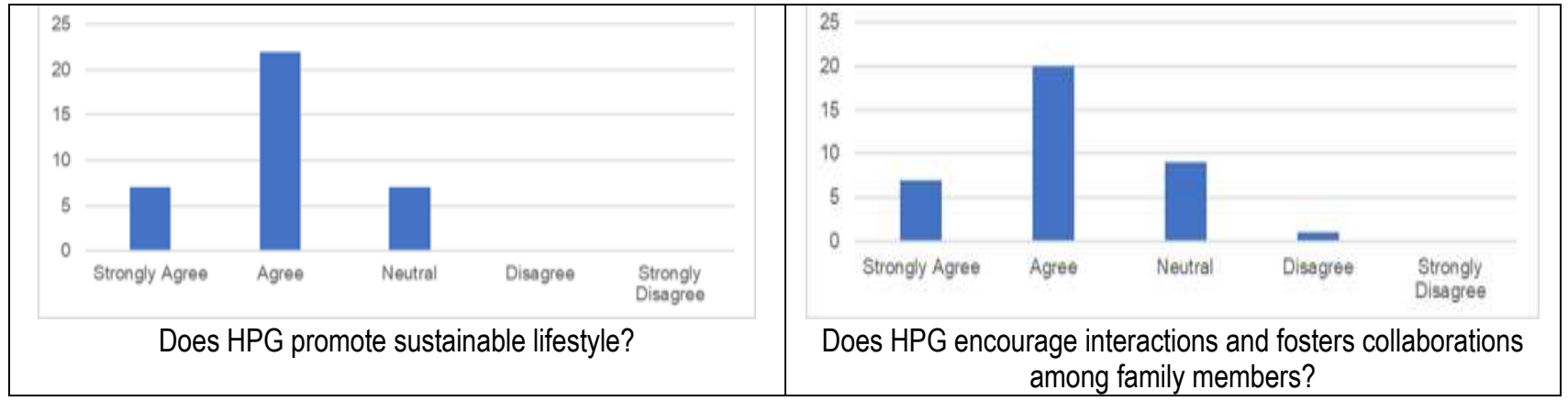

(a)

(b) 


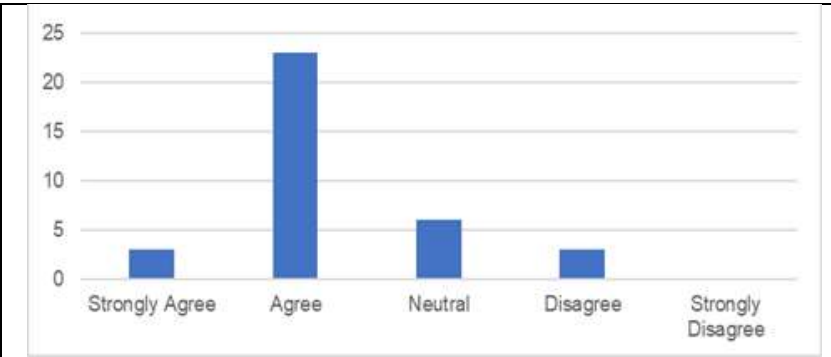

Does HPG encourage social interaction among neighbours?

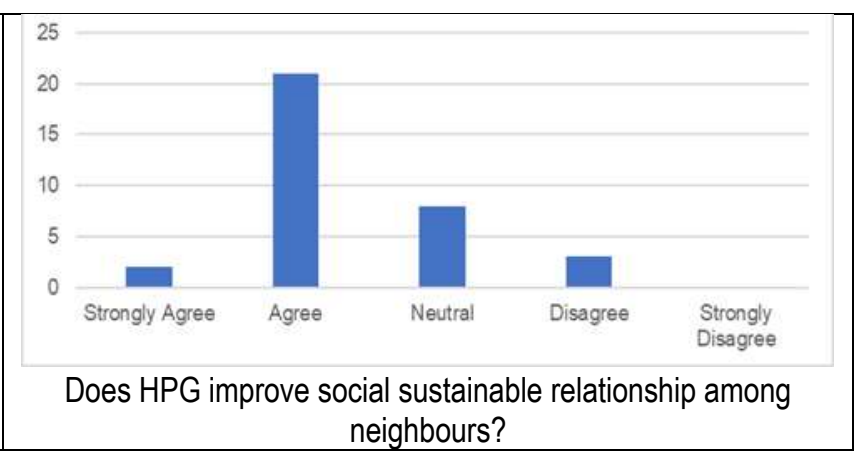

(d)

Fig. 15 (a), (b), (c) and (d): Perceptions on the impact of HPG on the sustainable cities and communities (SDG 11).

The findings in Fig. 15 (a), (b), (c), (d) show that HPG gives a positive role to the sustainable and communities (SDG 11), with a mean value of 3.7. The majority of the respondents believe that HPG plays a positive role in enhancing the quality of life for oneself and the neighbouring community. Another four of the survey questionnaires were related to the impact of HPG on good health (SDG 3 ).

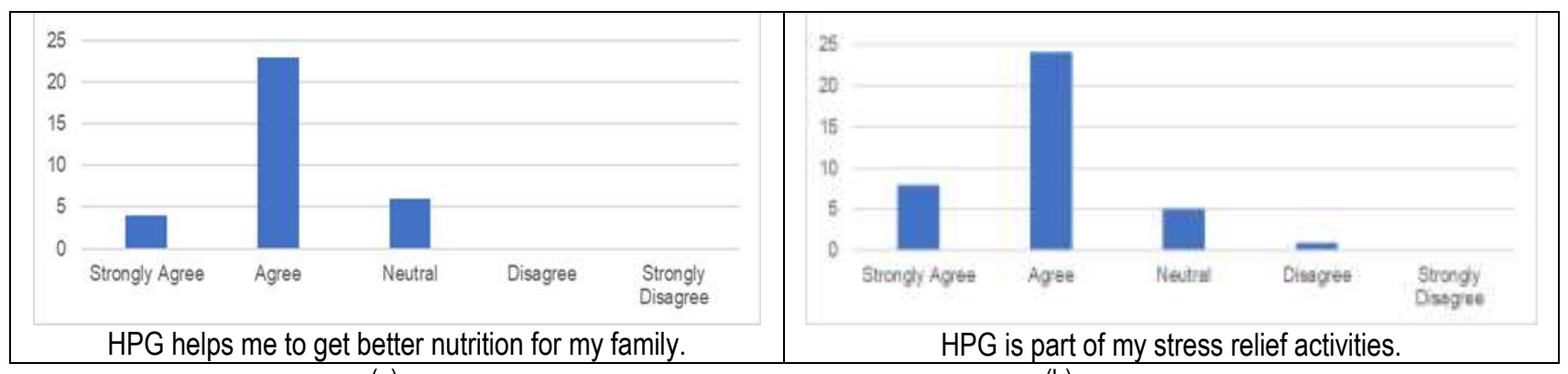

(a)

(b)

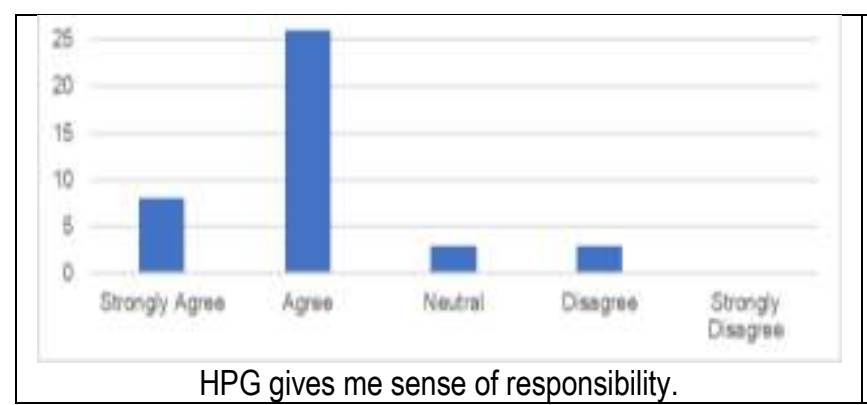

(c)

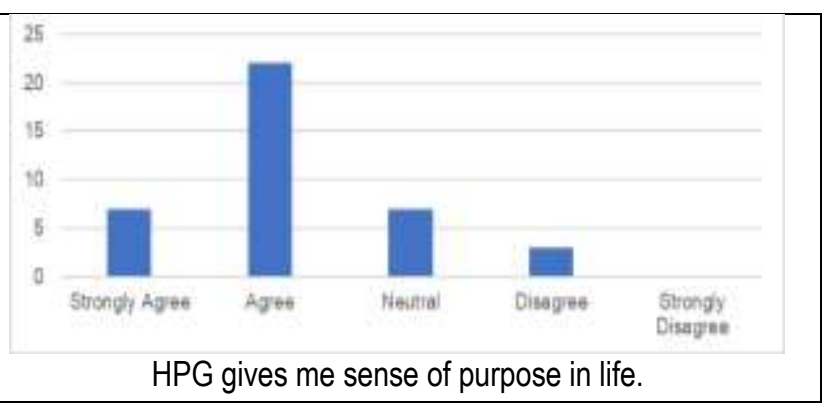

(d)

Fig. 16 (a), (b), (c) and (c): Respondents perceptions on the HPG impact on the good health and well-being (SDG 3).

Fig. 16 shows that the most significant impact of HPG according to the respondent is on good health and well-being (SDG 3), with a mean value of 3.8 .

\subsection{Discussion}

The findings have shown that Home Pocket Garden (HPG) plays a positive role in achieving Quality of Life (QOL) at home. Many houses have a Home Pocket Garden and implement gardening activities as part of their daily routine.

Most respondents have agreed that HPG plays a positive role in their health and well-being (SDG 3), with a mean value of 3.8. Most respondents also find the HPG provides their food security (SDG 2) with a mean value of 3.7. Furthermore, most respondents find the HPG provides a sustainable lifestyle and healthy social relationships among family members and neighbours (SDG 11), with a mean value of 3.7. As mentioned in Chapter 2, SDG 2, $3 \& 11$ are in line with the indicators of Quality of Life; They are Having, Loving, and Being (Allardt, 1993).

\subsection{Conclusions \& Recommendations}

The first conclusion answers the first objective. In conclusion, the housing community has ventured into various types of HPG. There were 12 different types of HPG. Some of the respondents installed hydroponics and rooftop gardens due to limited land area. They find the solution in implementing HPG in the limited open space area. In conclusion, the respondents who were satisfied with their HPG were those having $3 \mathrm{~m} 2$ or bigger HPG. Therefore, the study recommended having a minimum of $3 \mathrm{~m} 2$ for the HPG area. 
The second objective was to evaluate the significant impact of home pocket gardens on the quality of life (QOL) during the pandemic. HPG plays a positive role in maintaining the QOL during the pandemic. It responded to the Sustainable Development Goal in achieving food security (SDG 2), good health and well-being (SDG 3), and sustainable lifestyle and communities (SDG 11).

Further studies should be conducted on Home Pocket Garden (HPG). There should be architectural intervention in providing HPG friendly housing design \& planning to make HPG successful. It recommends each house have a minimum of $3 \mathrm{~m} 2$ of HPG..

This study also recommends HPG be developed into a community vegetable garden in the park to foster better relationships among the community. For future research, tree saplings can be distributed to each home in a community and investigate the role of tree saplings in improving the quality of life in their homes.

\section{Acknowledgements}

This study acknowledges the participation of Taman Bukit Bandaraya, Taman Mutiara Gombak 1 and Taman Bukit Utama.

\section{Paper Contribution to Related Field of Study}

The results highlight the importance of open green space areas for the well-being of residents in the current pandemic situation. This strengthens the need for local authorities to implement such policy in line with Planning Standard Guidelines for Open Spaces and Recreation (JBPD 7/2000) issued by FDTCP towards the "Garden Nation"

\section{References}

Al-Mayahi A., Al-Ismaily S., Gibreel T., Kacimov A., \& Al-Maktoumi A. (2019). Home gardening in Muscat, Oman: Gardeners' practices, perceptions and motivations. Urban Forestry \& Urban Greening, 38, 286-294. (Scopus)

Ali H. H., Malkawi F. K. \& Al-Betawi Y. N. (2009). Quality of Life in Cities: Setting Criteria for Amman-Jordan. Social Indicator Research, 93, 407-432.

Allardt E. (1993). Having, Loving, Being: An Alternative to the Swedish Model of Welfare Research. In Nussbaum M. and Sen A. (Ed.), The Quality of Life, 88-94. Oxford.

Amerio A., Brambilla A., Morganti A., Aguglia A., Bianchi D., Santi F., Constantini L., Odone A., Costanza A., Signorelli C., Serafini G., Amore M., \& Capolongo M. (2020). COVID-19 Lockdown: Housing Built Environment's Effects on Mental Health. International Journal of Environmental Research and Public Health, 17(16), 5973. (Scopus)

Bakar A. A., Malek N. A., Mohit M. A., Othman R., \& Sanusi A. N. Z. (2016). Housing Space Quality towards Quality of Life: A Case Study of Double Storey Terrace Houses. In: MATEC Web of Conference 66, 0083, IBCC 2016.

Dissanayake L., \& Dilini S. (2020). COVID-19 Outbreak and Urban Green Space, Food Security, and Quality of Life: Case of Urban Home Gardens in Kandy, Sri Lanka. Open Journal of Social Sciences, 8, 185-197.

Farid F. H. M., Ahmad S. S., Raub A. B. A., \& Shaari M. F. (2016). Green "Breathing Facades" for Occupants' Improved Quality of Life. In Procedia - Social and Behavioral Sciences, 234, 173-184. (WoS)

Hussein H., Ishak S. A., \& Yunus W. M. A. W. M. (2021). Does Spending Time in a Neighbourhood Park Reduce Stress? A preliminary psychological study. In AicQoL2021, AMER International Conference on Quality of Life, Colmar Tropicale, Bukit Tinggi, Malaysia, 17-18 Mar 2021, Environment-Behavior Proceedings Journal, E-BPJ, 6(16), 173-179. (WoS)

Ibrahim, P. H., Dali, M. M., \& Yusoff, S. Y. M. (2013). Implementation of Open Space: The Need for Uniform Policy. Journal of Sustainable Development, Vol. 6, No. 7, 1625.

Ismail A. S., \& Muslim M. M. (2017), An assessment of user perception towards the need of ecology design for middle income housing in urban context. Journal of Advanced Review on Scientific Research, 35(1), 8-24.

Krejcie, R.V., \& Morgan, D.W. (1970). Determining Sample Size for Research Activities. Educational and Psychological Measurement, 30, 607-610.

Omar E. O., Endut E., \& Saruwono M. (2012), Before and After: Comparative Analysis of Modified Terraced House. In Procedia - Social and Behavioral Sciences, 36, 158165. (WoS)

Rice R. W. (1984). Work and the quality of life. In S. Oskamp (Ed.), Applied social psychology annual. 5: Applications in organizational settings (pp. 155-177). Beverly Hills: Sage.

Triguero-Mas M., Anguelovski I., Cirac-Claveras J., Connolly J., Vazquez A., Urgell-Plaza F., Cardona-Giralt N., Sanyé-Mengual E., Alonso J., \& Cole H. (2020). Quality of Life Benefits of Urban Rooftop Gardening for People With Intellectual Disabilities or Mental Health Disorders. Preventing Chronic Disease, 17: 200087. (Scopus)

UBBL (2006) (14th edition), Laws of Malaysia Uniform Buildings By-Laws, 15, MDC

Vischer, J. C. (1989). Environmental Quality in Offices. New York: Van Nostrand Reinhold.

Vischer, J. C. (2015). The Effect of Workplace Design on Quality of Life at Work. In Fleury-Bahi G., Pol E., \& Navarro O. (Eds.), Handbook of Environmental Psychology and Quality of Life Research. London: Springer. 
Wegener, A., \& Huner, A. (2001). Quality of life indicator programs for strategic management in local government. Cities of Tomorrow Expert Workshop.

Williams C., \& Blaiklock A. (2015). SDG SERIES: With SDGs Now Adopted, Human Rights Must Inform Implementation and Accountability. Health and Human Rights, 9. (Scopus)

Zainudeen Z. T., Hamid I. J. A., Azizuddin M. N. A., Bakar F. F. A., Sany S., Zolkepli I. A., \& Mangantig E., BMJ Open (2021). Psychosocial impact of COVID-19 pandemic on Malaysian families: a cross-sectional study;11:e050523. doi:10.1136/bmjopen-2021-050523 